05

\title{
Высокодобротные магнитоэлектрические структуры никель-кварц-никель
}

\author{
(C) В.М. Лалетин ${ }^{1}$, Д.А. Филиппов ${ }^{2, q}$, С.Е. Мозжаров ${ }^{1}$, \\ И.Н. Маничева ${ }^{2}$ \\ ${ }^{1}$ Институт технической акустики НАН Беларуси, \\ Витебск, Беларусь \\ ${ }^{2}$ Новгородский государственный университет, Великий Новгород, Россия \\ ؟ E-mail: dmitry.filippov@novsu.ru
}

Поступило в Редакцию 1 ноября 2017 г.

Представлены результаты экспериментального исследования магнитоэлектрических характеристик трехслойных структур никель-кварц-никель в области электромеханического резонанса. Структуры изготовлены методом электролитического осаждения никеля на подложку из кварца. Установлено, что в области электромеханического резонанса они имеют высокую добротность $Q \approx 10000$, которая значительно превосходит добротность ранее изготовленных магнитоэлектрических структур. Данные эксперимента находятся в хорошем согласии с представленной ранее теорией.

DOI: $10.21883 /$ PJTF.2018.07.45880.17103

Магнитоэлектрические свойства слоистых магнитострикционнопьезоэлектрических структур обусловлены механическим взаимодействием магнитострикционной и пьезоэлектрической компонент. Для их изготовления в качестве магнитострикционной фазы выбираются материалы с большим коэффициентом магнитострикции, такие как никель, пермендюр, метгласс и др., а в качестве пьезоэлектрической фазы - материалы с большим коэффициентом пьезомодуля, такие как пьезокерамика цирконата-титаната свинца (PZT), магниониобататитаната свинца, кристаллы лантан-галлиевого танталата (лангатата), ниобата лития, титаната бария и др. [1]. Как показывают расчеты [2], величина магнитоэлектрического коэффициента $\alpha_{E}$ пропорциональна отношению пьезомодуля материала $d$ к величине диэлектрической проницаемости $\varepsilon$, т. е. $\alpha_{E} \sim\left(d / \varepsilon \varepsilon_{0}\right)$, где $\varepsilon_{0}-$ диэлектрическая постоянная. У большинства материалов высокое значение пьезоэлектрического 
модуля, как правило, сочетается с большим значением диэлектрической проницаемости. Например, для пьезокерамики PZT с большим значением пьезомодуля $d=100 \mathrm{pC} / \mathrm{N}$ и одновременно большим значением диэлектрической проницаемости $\varepsilon=1750$ отношение $\left(d / \varepsilon \varepsilon_{0}\right)$ равно $0.0065 \mathrm{~m}^{2} / \mathrm{C}$, для арсенида галлия с невысокими значениями $d=2.69 \mathrm{pC} / \mathrm{N}$ и $\varepsilon=13$ это отношение составляет $\left(d / \varepsilon \varepsilon_{0}\right)=0.024 \mathrm{~m}^{2} / \mathrm{C}$, а для кварца с $d=2.3 \mathrm{pC} / \mathrm{N}$ и $\varepsilon=4.5$ отношение $\left(d / \varepsilon \varepsilon_{0}\right)=0.05 \mathrm{~m}^{2} / \mathrm{C}$. Таким образом, использование арсенида галлия и кварца в качестве подложек для изготовления магнитоэлектрических структур должно приводить к бо́льшим значениям магнитоэлектрического (МЭ) коэффициента, чем для аналогичных структур на основе PZT. Этот факт для арсенида галлия экспериментально подтвержден в работах $[3,4]$. МЭ-эффект в структурах на основе кварца исследован в работе [5], где в качестве магнитострикционной фазы был использован пермендюр, а сами структуры изготавливались методом склеивания. Максимальное значение МЭ-коэффициента по напряжению (MEVC) в области электромеханического резонанса было равно $\alpha_{E, \max }=175 \mathrm{~V} /(\mathrm{cm} \cdot \mathrm{Oe})$ при добротности $Q=35$. Столь низкое значение добротности, с одной стороны, объясняется использованием при изготовлении структур промежуточного слоя (клея), который ухудшает механическое взаимодействие между слоями. С другой стороны, толщина магнитострикционного слоя в данных структурах была соизмерима с толщиной слоя пьезоэлектрика, что дает большое значение MEVC на низких частотах, однако одновременно снижает добротность системы, что приводит к недостаточно высокому резонансному значению коэффициента.

Задачей настоящей работы было изготовление и исследование структур, добротность которых превосходила добротность известных ранее структур. Для изготовления структур применялся метод электролитического осаждения. В качестве пьезоэлектрика использовались образцы, вырезанные из пластины кварца $(X$-срез) в форме параллелепипеда с размером $20 \times 4.5 \times 0.5 \mathrm{~mm}$. Магнитострикционный слой из никеля был получен методом электролитического осаждения. Толщина слоя никеля ${ }^{m} t$ с каждой стороны образца была равна 1,3 и $10 \mu \mathrm{m}$ для первого, второго и третьего образцов соответственно. Для сравнения в качестве модели методом склеивания была изготовлена трехслойная структура с толщиной никелевой пластинки ${ }^{m} t=250 \mu \mathrm{m}$. Исследовались частотные и полевые зависимости МЭ-эффекта методом регистрации переменного электрического напряжения на образце при помещении его в посто-

2 Письма в ЖТФ, 2018, том 44, вып. 7 


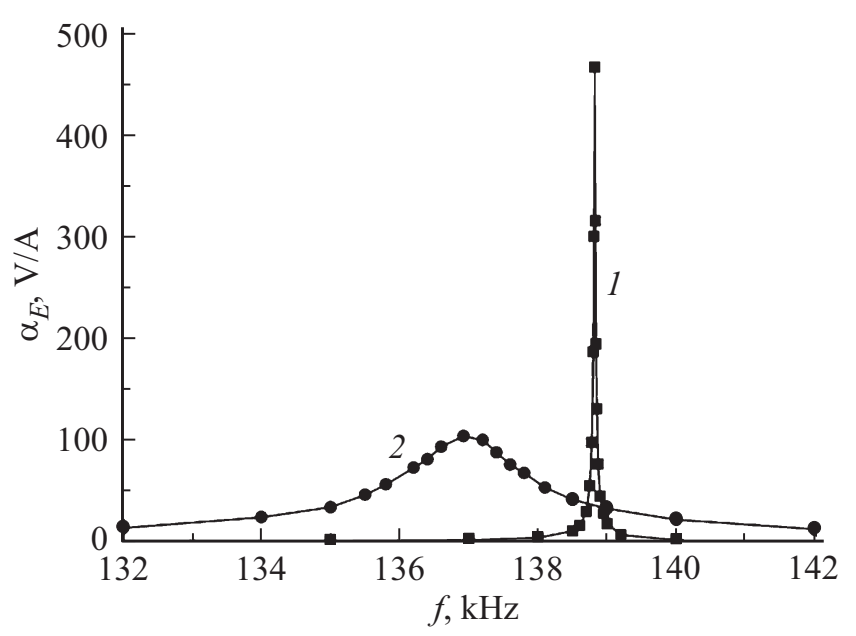

Рис. 1. Частотная зависимость MEVC. 1 - электролитическое осаждение никеля, ${ }^{m} t_{1}=10 \mu \mathrm{m} ; 2$ метод склеивания, толщина пластинки никеля ${ }^{m} t_{2}=250 \mu \mathrm{m}$.

янное подмагничивающее поле напряженностью $H_{\text {bias }}$ и переменное магнитное поле $H$, направленные вдоль длинной стороны образца. Исследования показали, что частотная зависимость МЭ-эффекта имеет ярко выраженный резонанс, частота которого определяется выражением $[6]$

$$
f_{\text {res }}=\frac{1}{2 L} \sqrt{\frac{m Y \cdot 2^{m} t+{ }^{p} Y^{p} t}{{ }^{m} \rho \cdot 2^{m} t+{ }^{p} \rho^{p} t}},
$$

где $L$ - длина образца, ${ }^{m} t,{ }^{p} t,{ }^{m} \rho,{ }^{p} \rho,{ }^{m} Y$ и ${ }^{p} Y-$ толщина, плотность и модуль Юнга магнитострикционного и пьезоэлектрического слоев соответственно. Резонансные значения MEVC для первого, второго и третьего образцов составляли 55, 150 и 475 V/A соответственно при добротности $Q \approx 10000$. Для модельного образца, полученного методом склеивания резонансное значение MEVC было равно $105 \mathrm{~V} / \mathrm{A}$ при добротности структуры $Q \approx 90$. На рис. 1 приведены частотные характеристики MEVC для образца, полученного электрохимическим осаждением никеля, и образца, полученного методом склеивания.

Письма в ЖТФ, 2018, том 44, вып. 7 




Рис. 2. Относительное изменение модуля Юнга никеля в магнитном поле. 1 - образец, полученный методом электролитического осаждения, толщина слоя никеля $10 \mu \mathrm{m} ; 2$ - образец, полученный методом склеивания, толщина слоя никеля $250 \mu \mathrm{m}$.

Результаты находятся в хорошем согласии с представленной ранее теорией [7]. Согласно ей, в низкочастотной области спектра значение MEVC пропорционально отношению $\frac{m_{Y \cdot 2^{m} t}}{m_{Y \cdot 2^{2} t+P^{p} t}}$. При малых толщинах магнитострикционного слоя, что имеет место в случае электрохимического осаждения, значение MEVC пропорционально толщине магнитострикционного слоя, что и подтверждается экспериментально. При толщинах магнетика, сопоставимых с толщиной пьезоэлектрической подложки, наблюдается отклонение от линейной зависимости. Подставляя значения модуля Юнга для никеля и кварца, получаем числовое соотношение, хорошо согласующееся с экспериментом. С увеличением толщины слоя никеля значение резонансной частоты уменьшается, что также согласуется с экспериментальными данными.

Большое значение добротности исследуемых структур можно объяснить тем, что магнитострикционный слой, полученный методом электролитического осаждения, имеет, с одной стороны, хорошую

2* Письма в ЖТФ, 2018, том 44, вып. 7 


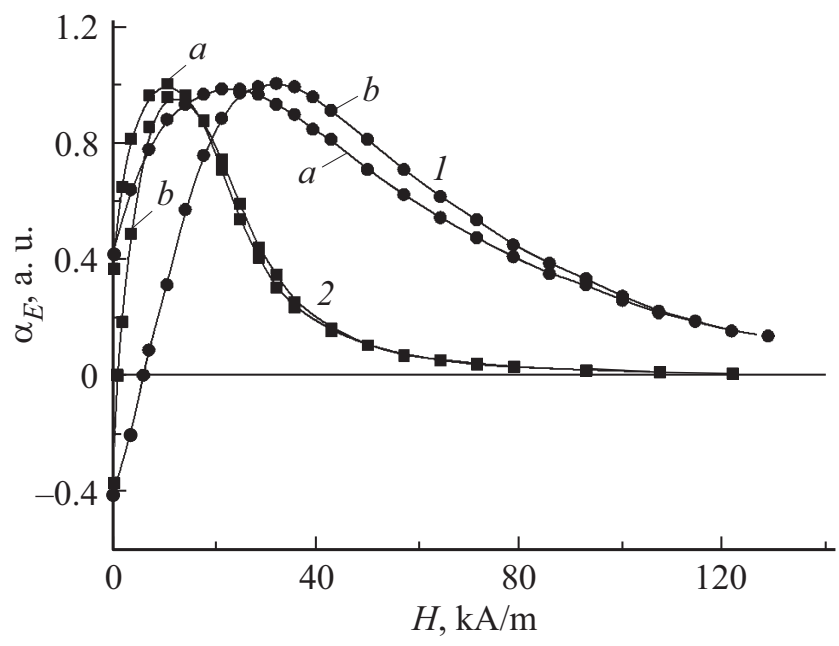

Рис. 3. Полевая зависимость относительного изменения MEVC при возрастании $(a)$ и убывании $(b)$ магнитного поля. 1 - образец, полученный методом электролитического осаждения, толщина слоя никеля $10 \mu \mathrm{m} ; 2$ - образец, полученный методом склеивания, толщина слоя никеля $250 \mu \mathrm{m}$.

адгезию и, как следствие, хорошую механическую связь с кварцем. С другой стороны, толщина магнитострикционного слоя существенно меньше толщины кварца, в результате чего он вносит незначительные изменения в высокодобротные характеристики кварцевой подложки.

МЭ-эффект можно использовать при исследовании механических характеристик магнитострикционной структуры, в частности модуля Юнга. Как следует из выражения (1), значение резонансной частоты структуры пропорционально модулю Юнга магнетика. При помещении структуры в магнитное поле происходит изменение модуля Юнга магнетика - так называемый $\Delta E$-эффект, в результате чего резонансная частота меняется. Поскольку структуры имеют высокую добротность, изменение резонансной частоты определяется очень точно, вследствие чего этот метод обладает высокой чувствительностью к изменению модуля Юнга. Как следует из (1), изменение резонансной частоты $\left(\Delta f_{\text {res }}\right)$, обусловленное изменением модуля Юнга магнетика $\left(\Delta^{m} Y\right)$,

Письма в ЖТФ, 2018, том 44, вып. 7 
определяется выражением

$$
\Delta f_{\text {res }}=0.5 f_{\text {res }} \frac{\Delta^{m} Y \cdot 2^{m} t}{{ }^{m} Y \cdot 2^{m} t+{ }^{p} Y^{p} t}
$$

Используя (2), для относительного изменения модуля Юнга получим следующее выражение:

$$
\frac{\Delta^{m} Y}{{ }^{m} Y}=2 \frac{\Delta f_{\text {res }}}{f_{\text {res }}}(1+\gamma)
$$

где введено обозначение $\gamma={ }^{p} Y^{p} t /\left({ }^{m} Y \cdot 2^{m} t\right)$.

На рис. 2 представлено относительное изменение модуля Юнга никеля при помещении структуры в магнитное поле для образцов, полученных электролитическим методом и методом склеивания.

Как видно из рисунка, в тонких магнитострикционных слоях, полученных методом электролитического осаждения, в области магнитных полей от 0 до $120 \mathrm{kA} / \mathrm{m}$ наблюдается отрицательный $\Delta E$-эффект. В то же время для толстых пластин отрицательный $\Delta E$-эффект имеет место лишь в малой области магнитных полей от 0 до $7 \mathrm{kA} / \mathrm{m}$, затем модуль Юнга возрастает и выходит на насыщение в магнитных полях свыше $40 \mathrm{kA} / \mathrm{m}$. Можно предположить, что данный результат объясняется доменной структурой магнитной фазы. В образцах, полученных методом склеивания, применялся изотропный поликристаллический никель. Пленки, полученные методом электролитического осаждения никеля, имели анизотропную столбчатую структуру. Косвенным подтверждением этого являются значения коэрцитивной силы на полевых зависимостях MEVC исследуемых образцов, представленных на рис. 3.

Как следует из рисунка, для тонкопленочной структуры с толщиной никелевого слоя $10 \mu \mathrm{m}$ величина коэрцитивной силы составила $6 \mathrm{kA} / \mathrm{m}$, в то время как для образцов с толщиной никелевой пластинки $250 \mu \mathrm{m}$, полученных методом склеивания, величина коэрцитивной силы была равна $\sim 1 \mathrm{kA} / \mathrm{m}$.

Таким образом, трехслойные структуры, полученные методом электролитического осаждения никеля на кварцевую подложку, обладают высокой добротностью $Q \approx 10000$, имеют резонансное значение MEVC, превышающее величину для аналогичных структур, полученных методом склеивания, и в области магнитных полей от 0 до $120 \mathrm{kA} / \mathrm{m}$ у них наблюдается отрицательный $\Delta E$-эффект.

Письма в ЖТФ, 2018, том 44, вып. 7 
Работа выполнена при поддержке гранта совместного конкурса РФФИ-БРФФИ (российский проект № 16-52-00184 и белорусский проект № Ф16Р-130).

\section{Список литературы}

[1] Srinivasan G. // Ann. Rev. Mater. Res. 2010. V. 40. P. 153-178.

[2] Филиппов Д.А., Лалетин В.М., Galichyan T.A. // ФТТ. 2013. Т. 55. В. 9. C. 1728-1733.

[3] Филиппов Д.А., Фирсова Т.О., Лалетин В.М., Поддубная Н.Н. // Письма в ЖТФ. 2017. Т. 43. В. 6. С. 72-77.

[4] Bichurin M.I., Petrov V.M., Leontiev V.S., Ivanov S.N., Sokolov O.V. // J. Magn. Magn. Mater. 2017. V. 424. P. 115-117.

[5] Sreenivasulu V.M., Petrov L.Y., Fetisov Y.K., Srinivasan G. // Phys. Rev. B. 2012. V. 86. P. 214405

[6] Лалетин В.М., Филиппов Д.А., Фирсова Т.О. // Письма в ЖТФ. 2014. Т. 40. B. 6. C. 11-18.

[7] Filippov D.A., Laletin V.M., Galichyan T.A. // Appl. Phys. A. 2014. V. 115. P. 1087-1091. 